\title{
THE IMPORTANCE OF A COMBINED 3D MODEL OF GROUND AND GEOTECHNICAL STRUCTURE
}

\author{
IVAN VANÍČEK*， DANIEL JiRÁSKO \\ Czech Technical University in Prague, Faculty of Civil Engineering, Thákurova 2077/7, 16000 Prague 6, Czech \\ Republic \\ * corresponding author: ivan.vanicek@fsv.cvut.cz
}

ABstract. The rapid progress of digitalisation in civil engineering is also happening in the branch of geotechnical engineering. BIM is a part of this process. The mutual connection of a $3 \mathrm{D}$ model of ground with a 3D model of geotechnical structure can help to give a clearer view of the interaction of this structure and ground. At the same time it also makes possible better control for all participants in the construction process, particularly if all conditions of this mutual interaction are fulfilled. There is considered whether the main aim of the construction process, namely that the care devoted to the individual phases of the structure design and execution actually correspond to the risk with which this structure and ground are indeed connected. Within this context a closer specification of the Eurocode 7 of the second generation will be identified, especially as it relates to different models.

KEYWORDS: 3D ground model, 3D model of geotechnical structure, BIM, phases of geotechnical investigation, principles of sustainable construction.

\section{INTRODUCTION}

Practical problems solved in geotechnical engineering have usually a 2D character. A typical example could be a flood barrier along a river or a long retaining wall. The design and execution of both of these geotechnical structures is based on the characteristic values of geotechnical parameters of the soil with which these structures interact. The problem is that on a relatively long section there may be a place where the geotechnical parameters used in the design are lower than expected and in this local place a failure may occur. In the case of a flood barrier (a dike, for example), a section $10 \mathrm{~m}$ long that breaks will in practice devalue the principle of the entire flood barrier, which can be as much as $10 \mathrm{~km}$ long. Of the various types of retaining walls, the gabion wall has the lowest stiffness in the third dimension, especially in comparison with conventional concrete. Therefore, it is easier to cause a local failure at the weakest point.

When a 2D Ground model is used, at least in the form of geological and geotechnical models of the subsoil, it is easier to identify these potentially dangerous places and thus prevent a loss of functionality. For earth structures of transport infrastructures, where it is a line construction, but where the third dimension is even more important than for a flood barrier (dike) because the width (third dimension) for higher fills or deeper cuts is more important, even though in reality the fault retains its local character, a typical example being the landslide on the motorway D8. Practically the same applies to linear underground structures, as in the case of tunnels.

From the point of view of the geotechnical construction itself, there is an interesting transition for earth and rock fill dams, for which in the ratio of the length of the dam to its height, it becomes more appropriate to use a $3 \mathrm{D}$ computational model. The reason is a more credible assessment of the potential danger of tensile cracking in the sealing of these dams.

For foundation structures, given the current more significant use of underground spaces (as for underground floors), the solution of a foundation structure in $3 \mathrm{D}$ is almost a necessity.

The current requirements for digitalisation in the construction industry, e.g. in the form of the use of BIM (Building Information Modelling), are thus met for geotechnical structures. The basic requirement is that the entire structure, i.e. not only the superstructure but also the subsoil and the foundation structures mediating the mutual interaction, be part of one common 3D model.

The interconnection thus brings to the fore the possibility of comparing the quality (informative value) of the subsoil model (whether geological or geotechnical) with the complexity of the superstructure, which can again be geotechnical, as already mentioned in earth structures or underground structures such as tunnels, galleries etc. At the same time, it meets the requirements of ČSN EN 1997 Design of Geotechnical Structures and the requirements for subsoil (ground) models obtained during different phases of geotechnical investigation.

\section{BIM}

One of the most widely used definitions of the BIM process is given by the American National Committee for the BIM Standard, which states that BIM is a digital description of the physical and operational characteristics of a facility. BIM is a shared source of knowledge and information about this device, creating 
a reliable basis for decision-making during its life cycle, defined from the first concept to demolition [1]. The emphasis is on two basic factors:

- It is a reliable basis for the decision-making process;

- It is a long-term process - covering the entire life of a building - from the concept itself to a final demolition.

Next, the main attention will be focused on the first factor, which in principle leads not only to a safe but also an effective construction design. All basic participants in the construction process can be part of this decision-making process, starting from the investor, and then on to the implementer of the geotechnical investigation, the designer, the supplier/contractor, and finally to the approval body, which comments on the construction. However, the second factor is no less important, as it mainly allows for time sequence and the continuity of individual steps, thus ensuring gradual development and specification. However, we must not forget the implementation of the principles of sustainable construction, which are currently strongly promoted [2, 3]. This means the possibility of assessing financial efficiency not only in the construction phase, but also in the demolition phase (i.e. through the entire life of the building). Therefore, lower demands on energy (plus $\mathrm{CO}_{2}$ footprints), lower land consumption as well lower demands on natural materials (by replacing them with non-standard materials) should be evaluated when total price is being determined.

The question of a reliable basis for a decision-making process and for the mutual cooperation of the main actors is present from the very beginning. In the first place, there is the investor's idea of the structure and the initial information about the ground on/in which this structure is to be situated. Today, even investors in supermarkets or warehouses understand that one standard, unified project of such a building cannot be put in place, at least without a minimum knowledge of the nature of the subsoil. In the same way, it is not possible to model the upper structure in $3 \mathrm{D}$ without relation to the ground/subsoil, respecting its replacement by various springs, as this is contrary to the basic principles of structural design, now clearly expressed in the system of Eurocodes for structural design. Finally, this is shown by the recommended name of Eurocode 0: Eurocode - Basis of structural and geotechnical design, defining the principles for the design of all building and civil engineering structures, including geotechnical - draft prEN1990, September 2020, which will replace EN 1990: 2002 [4].

Therefore, the importance of interconnected 3D models of the subsoil and the upper structure (whether it is a building or an engineering structure, including a geotechnical structure), is at the centre of current attention.

\section{Models Time Sequence}

The current valid version of Eurocode 7 - ČSN EN 1997 in part 1997-2 [5] in Annex B1 presents the following scheme for the stages of geotechnical/ground investigation of the foundation soil in the geotechnical design, the execution of work and the use of the geotechnical structure - see Figure 1

It is clear from this scheme that two basic parts are important within the geotechnical investigatory process:

- Providing a geological model (ground -subsoil, borrow pit), the main task of which is to divide the ground into different lithological layers with approximately identical properties, including different discontinuities, and also including information on the groundwater level.

- Ensuring the implementation of field or laboratory tests in the field of soil and rock mechanics for individual lithological layers.

The Geotechnical/Ground Investigation Report (GIR) is the main output of this process of geotechnical investigation.

Note. EN 1997 of the second generation uses not only the term geological model, but for this geological model supplemented by the results of field and laboratory tests, also uses the simple term Ground model. Although the English word ground has many possible meanings in Czech, it can probably be expected that it will be translated persistently as a model of the subsoil. Although for underground structures (tunnels, metro) it will probably be a more appropriate translation to say the rock environment model, and as well as for the earth structures to say the soil environment model.

Within the design of the geotechnical structure, two models come to the fore:

- The Geotechnical model - developed by the designer o the geotechnical structure after the evaluation of geotechnical parameters and coefficients.

- The Calculation model, when the analytical calculation model and the numerical calculation model come to the fore.

After the elaboration of the geotechnical structure project, the selection of the supplier and the actual implementation of all works will follow.

Note. In EN 1997 of the second generation the first model is labelled as "Geotechnical Design Model", which for each lithological layer specifies representative/characteristic values of the geotechnical parameters, and which are subsequently used in the calculation model.

From the point of view of time sequence, ground/geotechnical investigation becomes very important in respect to its phasing. Most often, and this 


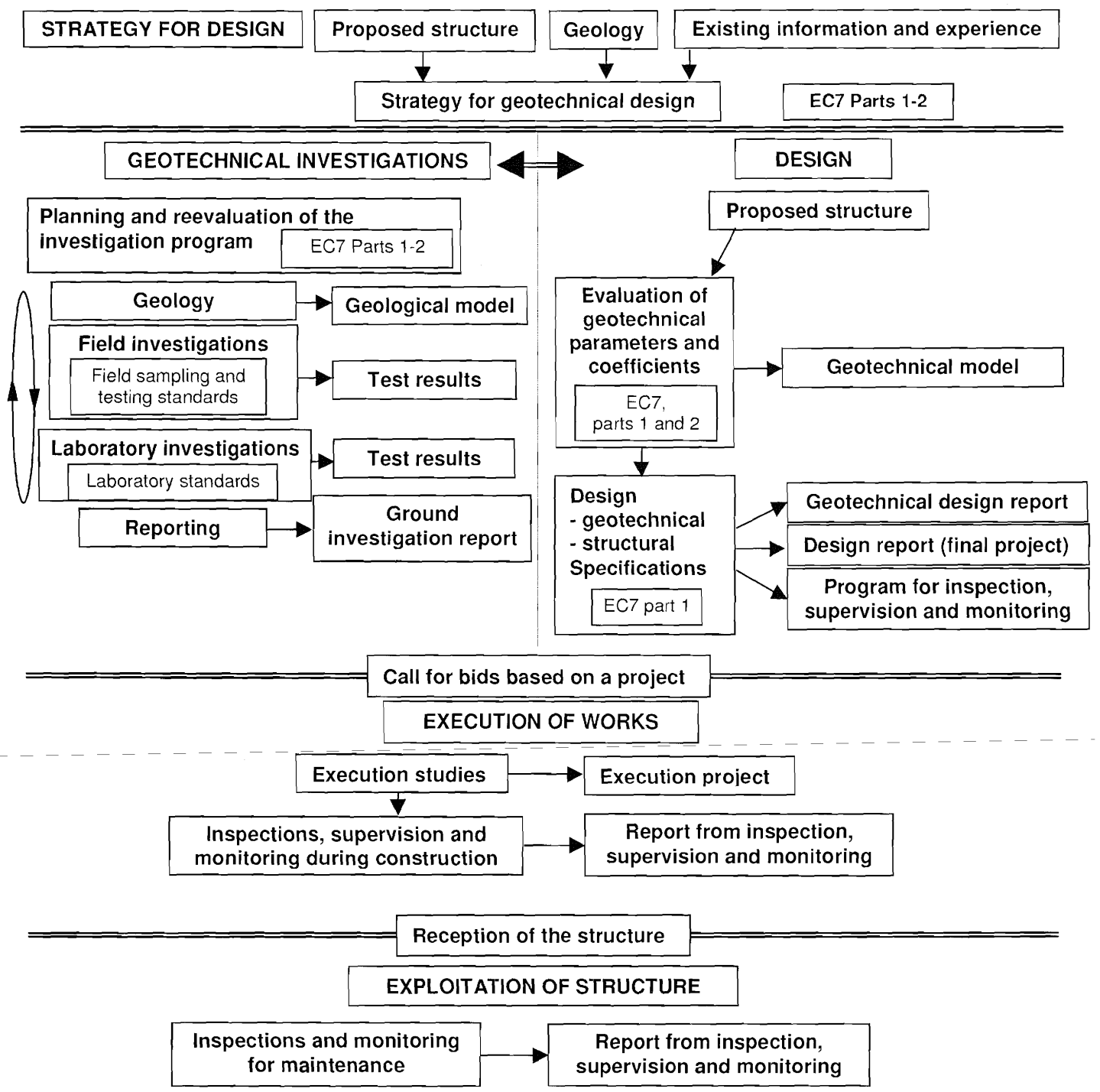

FIgURE 1. Stages of ground investigation in geotechnical design, execution of works and exploitation of the structure.

is also in the second generation EN 1997, for significant structures connected with high risk a distinction is made between:

- Desk study - a search of all available existing information from the point of view of the requirements of the geological and geotechnical model this phase is connected with the investment plan. In principle, it is based on all available map data - from geological, engineering-geological, hydrogeological to map data of a geo-environmental nature. Also it makes use of the database of survey points carried out so far in the area of interest. For significant public civil engineering structures, these documents can be used to evaluate various variants of location, with subsequent use for the EIA process. Therefore it is important, and this is supported by the CGtS CICE, that the data obtained so far can be used in such a form that would allow their quick placement in the 3D model of the subsoil for the first evaluation.

- Preliminary GI - the preliminary geotechnical/ground investigation - the investigation already uses survey methods, although only to a limited extent, which serves primarily to confirm the expectations obtained in the desk study and from the point of view of designing a geotechnical structure, it serves as a preliminary design for documentation for the zoning decision / project plan.

- Design (detailed) GI - detailed investigation, investigation for the geotechnical structure design this is the most important phase, as the results and conclusions are directly usable in the design of a geotechnical structure for the documentation phase regarding a building permit. 
- Supplementary GI - additional investigation is needed if during the execution phase larger deviations from the expected ones are found, which may affect both the actual technology of execution and any corrective calculation from the point of view of limit states.

- Confirmatory GI - a confirming investigation as an investigation of the actual state, important for comparing how sufficiently and credibly the investigation was in the first 3 phases and to what extent the designer used in the calculation model values very close to reality, or was too conservative, or too optimistic. This phase is typical for tunnels, also for foundation pits or for cuts of the earth structures of transport infrastructures, where the actual condition can be visually verified with the possibility of confirmation by additional tests. This possibility does not exist for the subsoil of embankments of earth structures.

It is natural that for simple structures with low risk, the phasing of the GI is reduced in exceptional cases to a one-stage survey, but the "desk study" phase should always take precedence for the collection of the existing data and the considered single stage investigation should complement or specify these assumptions.

\section{Mutual Interaction Between DiffERENT Steps of THE GRound Models With Models of THE Geotechnical Structure}

The importance of the first step, the evaluation of all available information, has already been mentioned, when for example for transport infrastructure structures, it has an influence on the choice of variants, as well as on the environmental impact assessment EIA. However, already at this stage it is possible to apply the principle of sustainable construction. Two issues can be mentioned in this regard.

The first one is connected with a recommendation whether the principle of reinforcement (for steeper slopes) will or will not be applied for the design of embankments and cuts. The question about required demands on land occupation and purchase become prominent as well the issue concerning volume of excavated and redeposited soil.

The second is related to the possibility of using large-volume waste such as construction and demolition waste, excavated soil, and rock excavated during construction of underground structures or underground garages, etc. Similarly, this applies to various wastes arising from the extraction of raw materials and their utilisation. This can significantly affect the issue of the balance of cubatures between cuts and embankments, where there is possibility of reducing the consumption of natural materials.

The second step - Preliminary GI focuses primarily on areas about which there is not so much prior information taken from the first step. The survey points should, in the first instance, provide sufficient information for the assessment of the individual lithological layers, when for these layers the term "geotechnical type" can be used as well. It is not only about layer interface but also about the basic properties of each layer, at least of a descriptive and index nature, when sometimes a set of results of these index properties can be used for a closer separation of individual lithological layers. This naturally also applies to information on filtration properties and groundwater levels, with respect to pore water pressures. However, with regard to the location of survey points and their depth, it is possible to use the recommendations in ČSN EN 1997-2 Annex B.3 [5]. At this stage, however, it can only be on the basis of experience when, for example for the foundation of bridge piers, it has not yet been decided whether they can apply spread or deep foundations (piles).

However, the preliminary GI should provide sufficient information for the designer's decision about foundation engineering. As for this decision the designer can realise the preliminary design according to the limit states based on so-called table values of the mechanical-physical geotechnical parameters utilising ground index properties or different classification systems, e.g. 6].

As field investigation methods have certain advantages in this respect, there is a tendency to prioritise them when their selection for different phases of the survey is specified in Annex B.2 in ČSN EN 1997-2 [5]. Similar tables of the mechanical-physical properties of soils can be used for the preliminary design of embankment and cut slopes. For embankments, information is obtained from the places from which this material will be used, as in borrow pits of cuts of transport infrastructures. When non-standard materials are used (such as large volume waste) a previously obtained experience can be applied. Preliminary design is used for the planning of the next step of geotechnical/ground investigation, as now the area affected by a proposed structure is more delineated.

On the third step, the step of detailed investigation, investigation for the geotechnical structure design is crucial. Additional survey points already use the preliminary design of the geotechnical structure, so they can fully follow the recommendations of CSN EN 1997 with regard to location and depth. At the same time, however, when planning this phase, it is necessary to divide the individual sections of the earth structure of transport infrastructure according to the risk and the class of consequences, and into different geotechnical categories. This division into geotechnical categories thus specifies the required scope and focus of field and laboratory tests. For sections falling into the 1st geotechnical category, the design can be implemented using previous experience and so descriptive and index properties in sufficient numbers for the individual lithological layer will suffice. Simply put, samples taken within the sampling category of class A and 
the quality class of samples 2 , in accordance with ČSN EN 1977-2, will suffice for laboratory tests. Naturally, it is also possible to use mechanical-physical properties obtained for neighbouring sections of the earth structure of transport infrastructure, and coming into a higher geotechnical category for the same lithological layer. For sections falling into the 3rd Geotechnical Category, the GI must be planned so that for each lithological layer it is able to provide a sufficient number of samples for statistical evaluation of the measured mechanical-physical properties for these lithological layers. The number of 5 samples is usually given as a minimum for statistical evaluation. The designer then decides (and is also responsible for) the representative/ characteristic value that he/she assigns to the individual lithological layer and is thus part of the "Geotechnical design model".

The fourth step has the function of further specification, often coinciding with the last step, and can significantly affect the final price of the structure brought on by a change in design or in the technology of structure execution.

The fifth step records the last findings on the properties of the ground/rock and soil environment and its $3 \mathrm{D}$ model together with a 3D model of the actual geotechnical structure or the whole structure and is the final output of the BIM model and serves for subsequent decisions over time throughout the life of this structure. For transport constructions, this is a decision regarding future interaction with another construction or in necessary decision-making in the case of accidents or disasters, where there is required quick decisions on the choice of remediation method in the event of an incident involving vehicles transporting hazardous substances.

\section{Conclusion}

The interconnection of 3D models of ground and geotechnical structures, whether foundation, ground or underground structures, is today referred to as the BIM model and is one of the outputs of digitisation in the construction sector. It is used for communication among partners in the gradual specification of individual phases associated with the geotechnical/ground investigation and geotechnical structure design. This eliminates possible errors, inaccuracies, and helps speed up the construction process and also defines the responsibilities of individual partners.

Attention is paid to the issue also because Government Resolution No. 82 "Concept of the introduction of the BIM method in the Czech Republic" specifies that all above-limit contracts financed from public budgets must be awarded in the BIM regime from 2022. This serves to point out the importance of a $3 \mathrm{D}$ model of the ground connection with a $3 \mathrm{D}$ model of the geotechnical structure, with an emphasis on transport infrastructure.

More precisely, the phasing and gradual refinement of the BIM model according to the individual phases of geotechnical/ground investigation in connection with the individual phases of the geotechnical structures design has been shown. This is a preference for earth structures such as embankments and cuts and for foundation structures in the designing of transport structures. This is accomplished while respecting the principles of geotechnical structures design according to ČSN EN 1997 [5], in terms of risk, geotechnical categories, and in terms of requirements for the sampling class or sample quality class.

\section{REFERENCES}

[1] I. Vaníček, J. Pruška, D. Jirásko. BIM Model Application in geotechnical engineering. (in Czech). In: Proc. $47^{\text {th }}$ Conference on Foundation Engineering Brno 2019, s. 91-98.

[2] I. Vaníček. Sustainable Construction. Czech Technical University Press, Praha, 2011.

[3] I. Vaníček, D. Jirásko, M. Vaníček. Modern Earth Structures for Transpor Engineering. Engineering and Sustainability Aspects. CRC Press, Taylor and Francis Group, London, 2020, 171 p.

[4] Eurocode. Basis of structural and geotechnical design. Draft prEN1990, September 2020.

[5] ČSN EN 1997. Eurocode 7 Geotechnical design (in Czech Navrhování geotechnických konstrukcí. 1997-1, 1997-2, 2006, 2008.

[6] A. Bond. Eurocode 7: Half-Term Report. (Invited Lecture), 41st Conference on Foundation Engineering. Brno, 11th November. 